\title{
An Adaptive Photovoltaic Topology to Overcome Shading Effect in PV Systems
}

\author{
Mohamed Amer Chaaban, ${ }^{1}$ Lana El Chaar, ${ }^{2}$ and Mahmoud Alahmad \\ ${ }^{1}$ Durham School of Architectural Engineering and Construction, PKI, University of Nebraska-Lincoln, \\ 1110 S. 67th Street, Omaha, NE 68182, USA \\ ${ }^{2}$ GE POWER \& WATER, Toronto, ON, Canada M5J $2 \mathrm{M} 2$
}

Correspondence should be addressed to Mahmoud Alahmad; malahmad2@unl.edu

Received 20 November 2014; Revised 3 March 2015; Accepted 3 March 2015

Academic Editor: Mahmoud M. El-Nahass

Copyright (C) 2015 Mohamed Amer Chaaban et al. This is an open access article distributed under the Creative Commons Attribution License, which permits unrestricted use, distribution, and reproduction in any medium, provided the original work is properly cited.

\begin{abstract}
Shading in photovoltaic systems can cause many undesired effects. When shading occurs, the power generated from the PV system is much less than nominal power, increasing the electrical mismatching losses between PV system components. Active research to address this power loss focuses on static and adaptive systems. This paper addresses an adaptive system solution and proposes a new method to adaptively overcome losses due to shading during low radiation conditions. In addition, a statistical analysis for choosing the most feasible and efficient configuration for the system size is presented. The proposed system has been validated under shade conditions in a simulation and prototype experiment. The experiments are conducted using a PV system consisting of 10 PV modules located at the Petroleum Institute in the United Arab Emirates. The proposed system is shown to minimize the shading losses of the PV array in real time by an average of $100 \%$ under simulated conditions and $84 \%$ in practical experiments.
\end{abstract}

\section{Introduction}

Recent forecasts by IEA (2014) indicate that the electricity is the fastest-growing final shape of energy with increased demand worldwide [1]. Interest in renewable energy is growing as more people work to build a "greener" and more energy sustainable future where the demand for electricity is met. Solar, wind, hydro-, geothermal, tidal, and biomass power can be harnessed from renewable energy sources for the creation of this future. Solar energy is an abundant and as stated in [2] "the solar energy that hits the earth's surface in one hour is about the same as the amount consumed by all human activities in a year." Since sunlight can be converted into electricity through the use of the photovoltaic effect, a whole market has arisen which caters to the demand for solar power. This global solar photovoltaic (PV) market has experienced vibrant growth for more than a decade since the year 2000, sporting an average annual growth rate of $40 \%$ with continued significant potential for long-term growth. Tracking the recorded PV installation, IEA [2] found that the cumulative installed PV power capacity has grown from 0.1 GW in 1992 to $14 \mathrm{GW}$ in 2008 . Furthermore, since 2010 , the world has added more solar photovoltaic (PV) capacity than in the previous four decades. Total global capacity overtook 150 gigawatts (GW) in early 2014 [2]. Today, photovoltaic power provides $0.1 \%$ of the total electricity generated worldwide. Although this amount is relatively small, thanks to recent dramatic cost reductions, the use of PV power, based on flatplate collectors and building integrated photovoltaic systems as photovoltaic based distributed generation (PVDG) [3], is beginning to rapidly expand in all sectors including building incorporated photovoltaic (BIPV) systems [4] and for onroad driver monitoring system in a car [5]. According to the 2014 vision of the International Energy Agency [2] by 2050, PV will provide $16 \%$ of the world's global electricity production, corresponding to 4600 gigawatts of cumulative installed PV capacity. This will eliminate 4 gigatons (GT) of $\mathrm{CO}_{2}$ emissions per year [2]. By 2050, the IEA hopes to attain a $50 \%$ reduction in $\mathrm{CO}_{2}$ emissions and $20 \%$ of this reduction is expected to come from PV [2]. For example, an assessment study for a Lisbon suburb found that the potential installation of $7 \mathrm{MW}$ at 538 identified building will produce 
11.5 GWh/year [6]. In its 2014 annual energy outlook, EIA [7] sees solar photovoltaics and wind power dominating new commercial distributed generation capacity, accounting for $62.3 \%$ of commercial capacity by 2040 and a PV increase of $5.7 \%$ /year from 2012 to 2040 in the reference case.

Current research in the PV field focuses upon improving the efficiency of PV cells through the development of new, better performing semiconductor structures. After deployment, scholars are currently looking to improve the performance of PV systems by tracking the optimal operating conditions and adaptively reconfiguring the system topologies and implementing power electronic devices to help the system operate more efficiently. One such targeted issue is the dissimilarities that arise when some modules are shaded or as a result of manufacturing differences in the $I-V$ characteristics of each module. Since each PV module has a different MPP, this dissimilarity may result in a reduction in the total amount of power harvested [8]. In other words, the PV system interface and the connections and configuration of the components play a vital role, along with the operational conditions (shadowing, high temperatures, and degradation of the electrical characteristics of damaged panels), in determining the whole system performance. These conditions, electrical mismatching losses, can occur between the system components (such as between the PV modules and power conditioning units) during abnormal operating conditions. The presence of shade on one or several modules or even on a part of one module will result in less energy generation of the entire array and in increasing the electrical mismatching losses between the system components. Furthermore, the shading may create local hot spots in the shaded part of the PV system which may result in permanent damage not only to the shaded solar cells but also for the entire module housing these cells.

To address these issues, the research community is developing static and adaptive solutions at the cell, module, and panel level. Examples of using static solutions include the use of bypass diode(s) connected in parallel with PV cells/modules for the purpose of passing full current while preventing damage during partial shading. This method usually requires the use of a number of bypass diodes depending on the implementation at the cell or module level. However, the production of systems with bypass diodes is costly and losses are not completely prevented because of the power losses that occur when current passes through these bypass diodes. Another example involves the use of DC/DC converter at the string level to individually operate each string near its own maximum power point (MPP). This method improves the efficiency of the entire system but requires the use of a greater number of DC/DC converters (an amount equal to the number of PV strings used). Examples of using adaptive solutions include developing adaptive topologies, and the subject of this research paper can be reconfigured to accommodate real-time conditions.

The adaptive topology approach reconfigures the module/panel/string connections to track the maximum power output and set the system to perform optimally in real time. In [8], the authors proposed a modular DC/DC converter topology to reduce the number of $\mathrm{DC} / \mathrm{DC}$ components that track the MPP used in stand-alone PV systems. A drawback of this topology is that it requires all PV modules to work in parallel and thus may not be applicable in large scale installations. In [9], the authors discussed a reconfiguration at the cell level that addresses the effects of shading. Through the addition of external reconfigurable cells, the authors are able to increase the output power. Dissimilar cells are matched through reconfiguration for the purpose of improving the efficiency of the system. This is accomplished through the reconfiguration of a large number of switches and sensors at the cell level $[10,11]$. An electrical array reconfiguration (EAR) is proposed in [12] at the module level using a switching matrix that can change the position of the PV modules and enable better matching between those that are similarly illuminated. The system is used to maximize the available DC power by matching modules that have similar operating conditions. A reconfiguration is proposed in [13] for an electric vehicle to increase its power output, operate the load at the desired conditions, and improve upon the efficiency of the load. During acceleration, for example, PV modules can be reconfigured into a parallel arrangement to increase the current output of power to an engine that requires additional torque. In [14], the authors proposed optimum switching points for the array reconfiguration controller according to the insolation conditions. In [15], the authors propose a reconfigurable PV module with internal integrated switches and, in [16], a new dynamic method based on the string-configured topology is proposed.

This paper proposes a novel method to adaptively decrease the electrical mismatching losses in a grid connected PV systems using an adaptive reconfiguration approach. The paper is organized into three sections. Section 2 describes the proposed method and the operational conditions. Section 3 provides analyses and compares the differing topologies and gives the results of simulated and experimental model used to verify the proposed approach. Finally, a summary and conclusion are given in Section 4.

\section{Proposed Adaptive Photovoltaic System}

The proposed adaptive photovoltaic system is based on ongoing research in the development and application of a novel flexible switch matrix (FSM) in [17-19]. The FSM provides features for dynamically connecting adjacent elements, such as PV modules, in parallel, series, or parallel/series configurations and even selective element isolation. FSM can be incorporated into a string-inverter topology with additional microinverter modules to form the proposed topology. The topology is composed of three subsystems as shown in Figure 1: subsystem 1 that consists of a flexible switch matrix (FSM) topology, subsystem 2 that consists of flexible microinverter modules (FMIMs), and subsystem 3 that consists of the main string-inverter modules (MSIM) that form the three flexible strings (FST). The topology also includes flexible string parallel switches $\left(S_{\text {st,inv }}\right)$ and flexible micro string parallel switches $\left(S_{\mathrm{mr}, \text { inv }}\right)$ which are used to optimize the operation of the system during uniform low insolation conditions. 


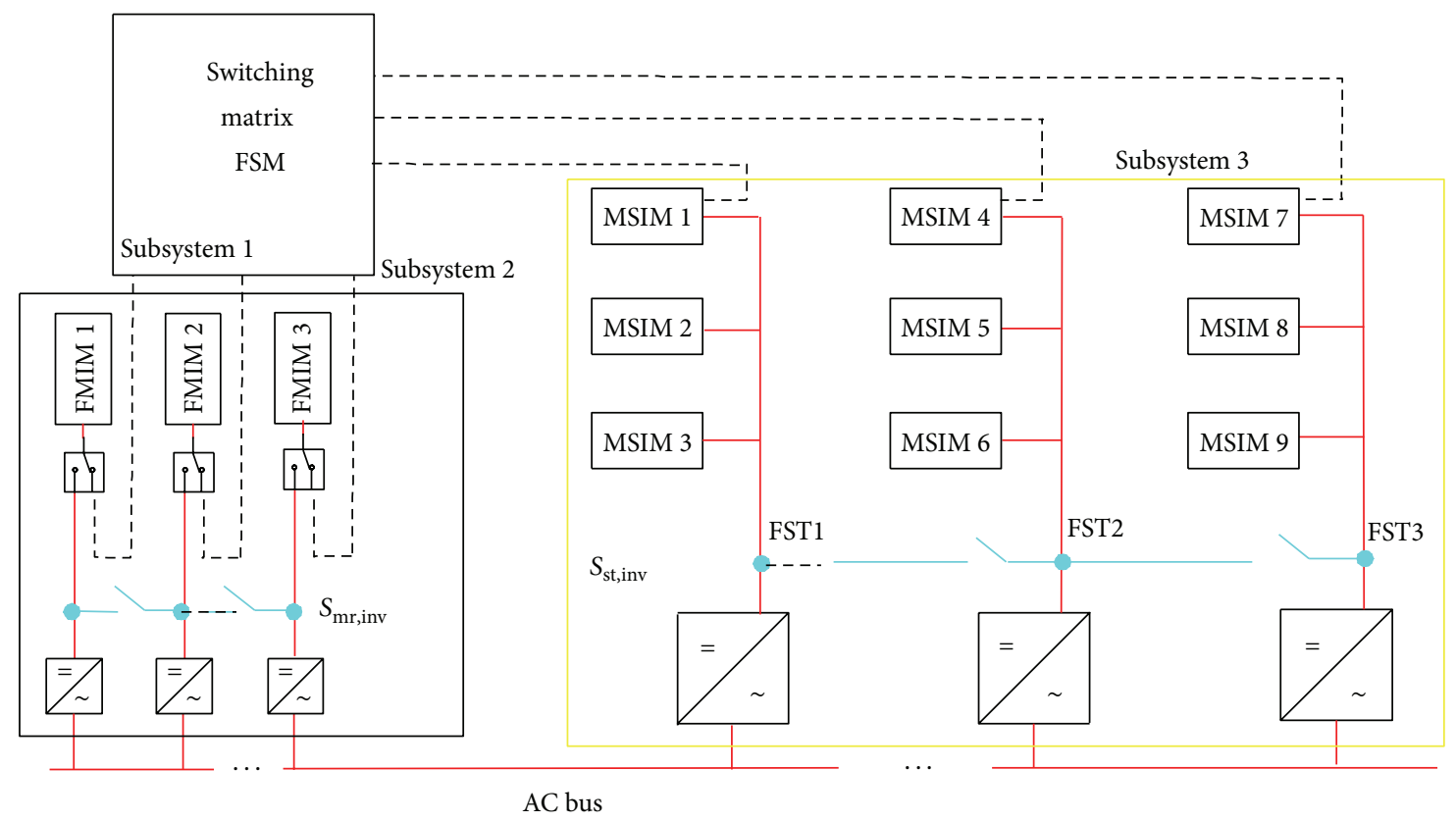

FIGURE 1: Layout of the adaptive PV string-inverter configuration with three flexible strings (FST) forming the MSIM and three microinverter modules (FMIMs).

The number of switches $\left(N_{\text {switches }}\right)$ required inside the FSM is calculated based on

$$
\begin{aligned}
N_{\text {switches }}= & N_{\text {FST }} \times 6+N_{\text {FMIM }} \times 3+\left(N_{\text {FST }}-1\right) \\
& +\left(N_{\text {FMIM }}-1\right),
\end{aligned}
$$

where $N_{\mathrm{FST}}$ is the number of flexible strings and $N_{\mathrm{FMIM}}$ is the number of flexible microinverter modules (FMIMs) in the system.

2.1. Operation. Figure 2 illustrates the different operational conditions under which the proposed topology can be employed for a system with two FSTs and three FMIMs. Figure 3 is a flow chart of the control logic that explains the steps of the reconfiguration in detail. As shown in Figure 2(a), under normal operating conditions, the FMIMs are connected to their respective microinverter(s) and the FSTs are connected to their respective string inverter(s). Both subsystems are connected in parallel to the AC bus. If radiation is present at very low levels (Figure 2(b)), multiple FSTs can be connected to one string inverter, to minimize the number of inverters, using parallel switches $\left(S_{\text {st,inv }}\right)$ and FMIM connected in parallel using parallel switches $\left(S_{\mathrm{mr} \text {,inv }}\right)$. Since it reduces the number of active inverters and creates an increase in the input energy of each active inverter, the FST reconfiguration both optimizes the system and improves its efficiency.

The following scenarios may occur under conditions in which shade is present: shading across one FMIM; shading across multiple FMIMs; shading across one MSIM in the FST; shading across multiple MSIMs in one FST; or shading across multiple MSIMs in multiple FSTs. When shading occurs across only one FMIM as shown in Figure 2(c), the FSM will not be modified since the effected module is connected to its own MPPT and DC/AC inverter. This is due to the fact that while the FMIM is performing at a lower voltage and/or current output, it will not affect the other modules since it has its own DC/AC inverter. The same is true when multiple FMIMs are shaded. When shading occurs across one MSIM in the FST as shown in Figure 2(d), the system will utilize one FMIM and connect it in series with the MSIM to form a complete FST. This is done in order to match the voltage/output requirement and ensure the system operates at its maximum capacity. When shading occurs across modules in different FSTs as depicted in Figure 2(e), multiple FMIMs will be connected to the shaded FSTs in order to maintain the nominal operating conditions for each FST. Any remaining FMIMs are connected to their own microinverters. In this case, the $P-V$ curves will still have multiple peaks, but the shading problems can be fixed with a minimal number of switches and a small number of the required $I, V$ measurement sensors.

2.2. Optimizing the Proposed Configuration. Figure 4 shows the different possible configurations for the proposed topology according to the number of modules per string and number of strings that form a PV system. For example, a 40-module PV array system can be formed with three FSTs and 10 MSIMs in each string and 10 individual FMIMs and microinverters. This configuration, when incorporated with the FSM, will utilize 59 switches. The 40 -module system can also be configured with four FSTs with eight MSIMs in each string and eight individual FMIMs and microinverters. This configuration, when incorporated with the FSM, will require in total of 58 switches. As an alternative, the array can also be configured with seven FSTs with five MSIMs in each string 


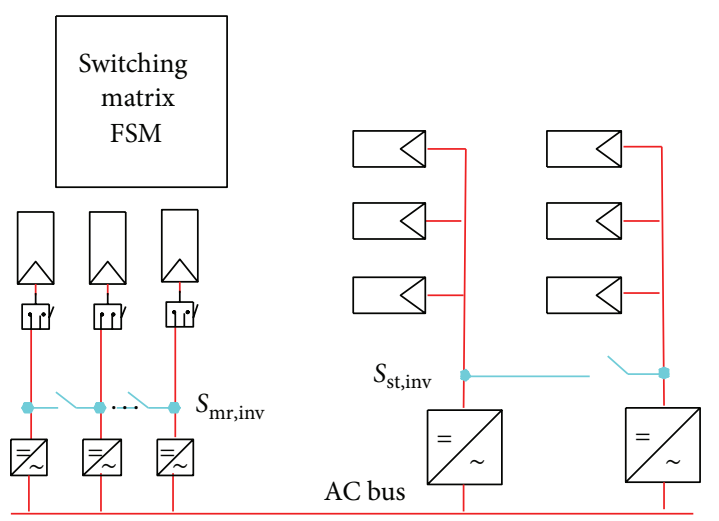

(a) Normal operation configuration

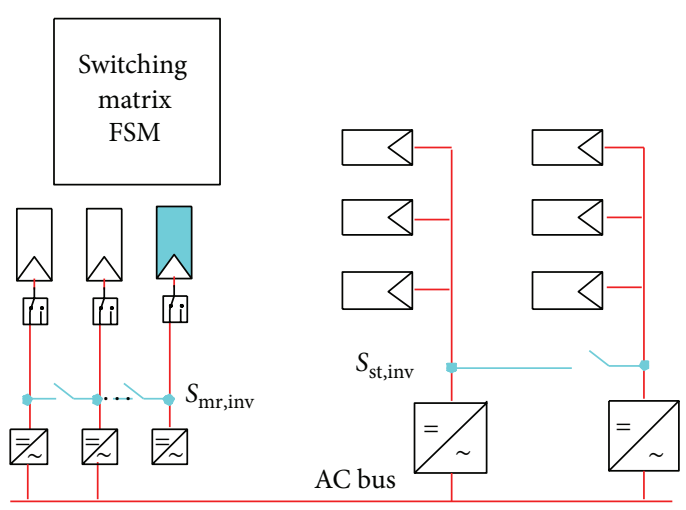

(c) One shaded FPVM

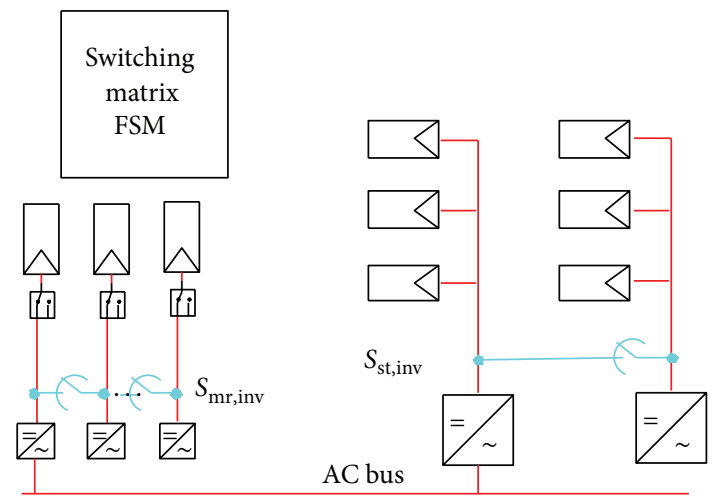

(b) Low radiation

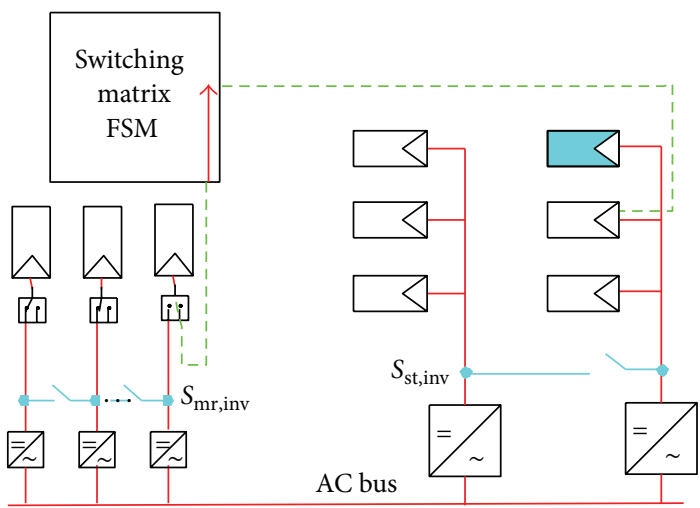

(d) One shaded module

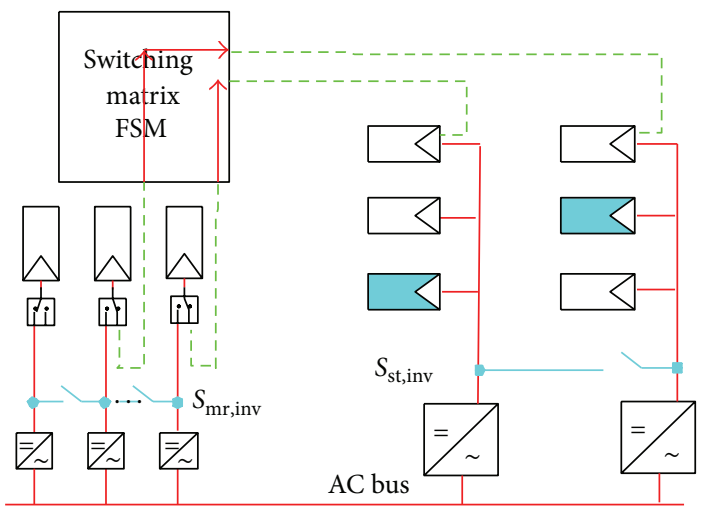

(e) Two shaded modules

FIGURE 2: The adaptive PV string-inverter configuration under differing operating conditions.

and five FMIMs with five individual microinverters. This configuration, when incorporated with the FSM, will require 67 switches. As a result, the option that requires the use of the fewest number of switches will be the best. Figure 4 provides an illustrative tool for helping to determine the optimal configuration according to the system per unit [p.u.] and number of switches. As can be seen, each curve represents the possible configurations according to the number of FMIMs and MSIMs per string. The interconnections between the curves denote points that have the same system size (on the $x$-axis) and number of switches (on the $y$-axis).

\section{Results, Analysis, and Comparisons}

3.1. Simulation Analysis. Manufacturers of PV modules provide module characteristics to include the open circuit voltage, short circuit current, maximum power point voltage, and current and power output at standard test conditions (STC). This information is used to simulate the currentvoltage $(I-V)$ and power-voltage $(P-V)$ curves. The current in the equivalent circuit of the PV cell which can be expressed as a function of the module output voltage. This information is being used by researchers along with other variables to 


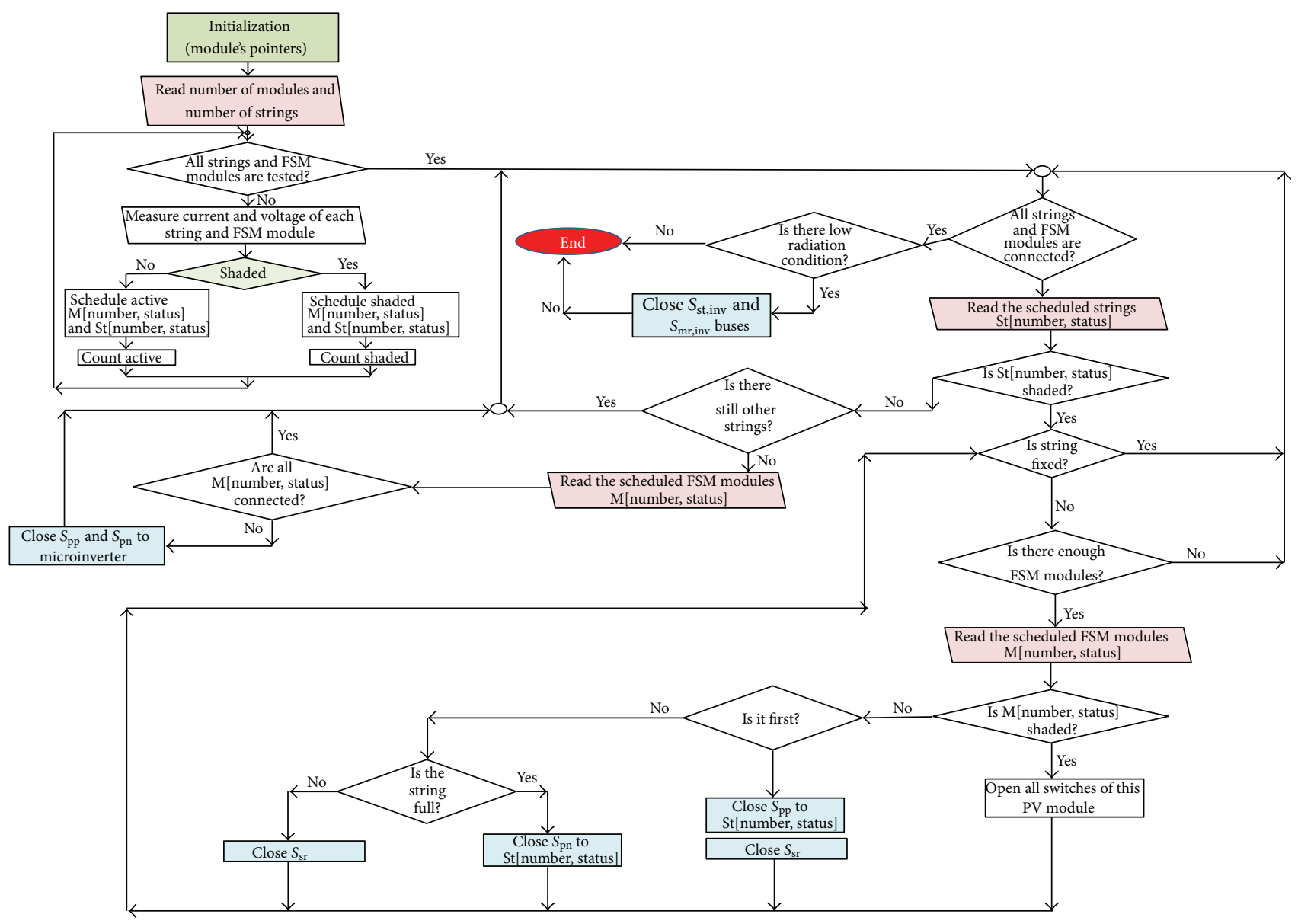

FIgURE 3: Adaptive PV string-inverter configuration control flow chart.

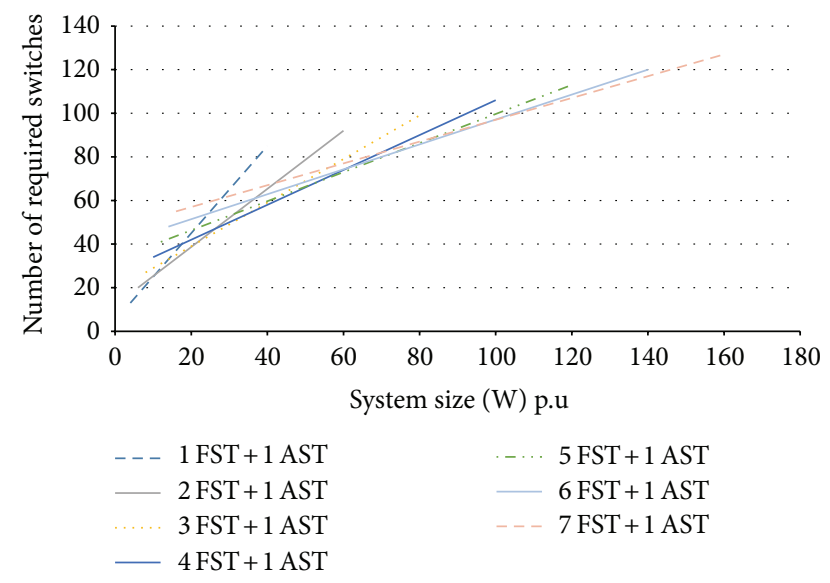

FIgURE 4: Configuration optimization flow chart according to system per unit and number of switches.

simulate the PV system using various simulation tools. The authors in [20] developed an integrated thermal and electrical model to accurately reflect real-time conditions. A new approach for simulating $I-V$ and $P-V$ curves was achieved in $[21,22]$ at the single scale level (such as for a PV cell, module, or array). The model can generate satisfactory results if manufacturer provided data is used. While the model is effective for simple cases, it cannot simulate a real PV system under differing operational conditions such as when shading occurs across some of the modules in a single or parallel string. Thus, the model cannot be used to simulate all adaptive cases.

To solve this problem, another simulated model (the one used in this work) is developed in [23]. Implementing this model will allow the features of the proposed adaptive system to be achieved. The model is based on a group concept and simulates the real array cases of different insolation and shadowing effects. The inputs of each group are adjustable. The solar irradiance, temperature, and number of parallel strings in each group serve as inputs. A MATLAB simulation model and an actual test were conducted to verify the proposed topology using two strings of three series connected PV modules of $50 \mathrm{~W}$ each. The simulation separately analyzed the effects of shading over one, two, and three PV modules from different strings. Figure 5 gives the results of the simulation for the traditional and proposed systems. As can be seen in Figure 5(a), under shade conditions, the $P-V$ curve of the traditional system will have multiple peaks. These peaks are indicative of system losses. Figure 5(b) shows that 

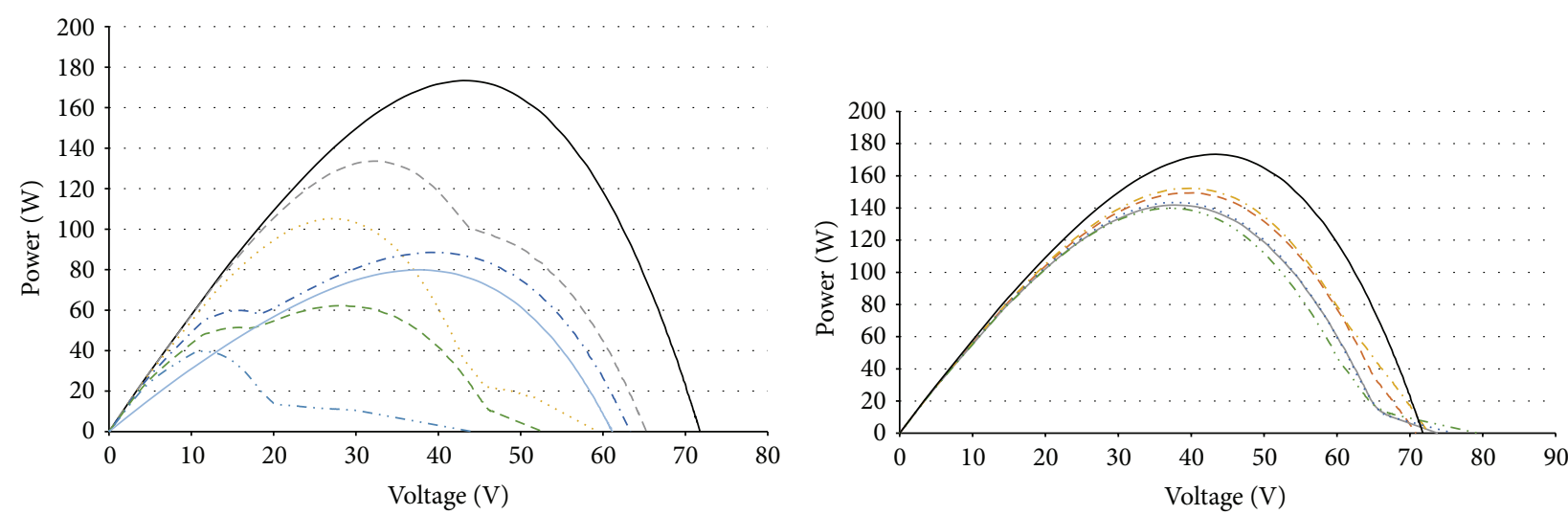

- Normal 2 strings

2 shaded fixed modules ( 1 from each string)

- - 3 shaded modules ( 1 from 1 st and 2 from 2 nd string)

- -.. 4 shaded modules, 2 from each string

- - 1 shaded fixed module

-.. 2 shaded modules from 1 string

_ 3 shaded modules from 1 string

(a) Traditional system $P-V$ curves

- 1 shaded adaptive module

- - 2 shaded (from 1 string) adaptive modules

. ... 4 shaded (2 from each string) adaptive modules

- 2 shaded adaptive modules ( 1 from each string)

3 shaded (1 from 1 st string and 2 from 2 nd string)

advaptive modules

- Normal 2 strings

(b) Adaptive system $P-V$ curves

FIGURE 5: Simulation results for traditional and proposed systems for various shading patterns.

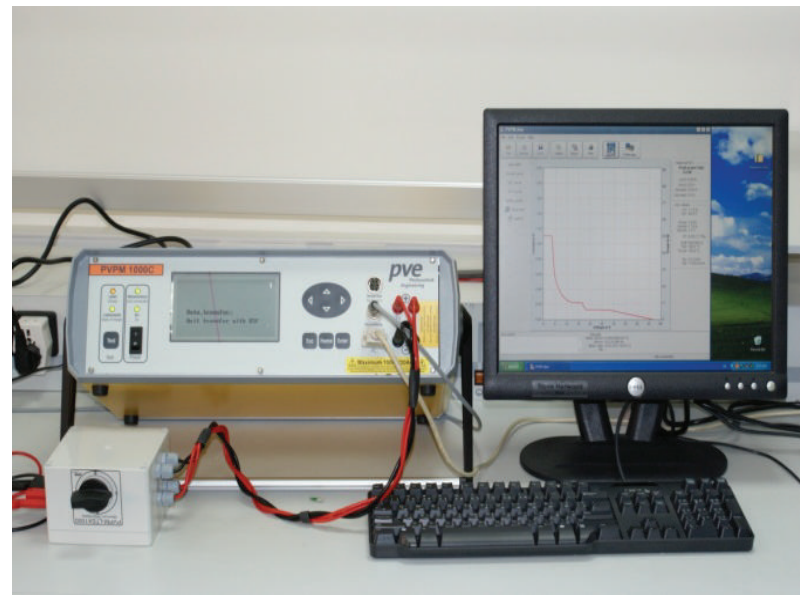

(a) $I$-V tracker model number PVPM 1000
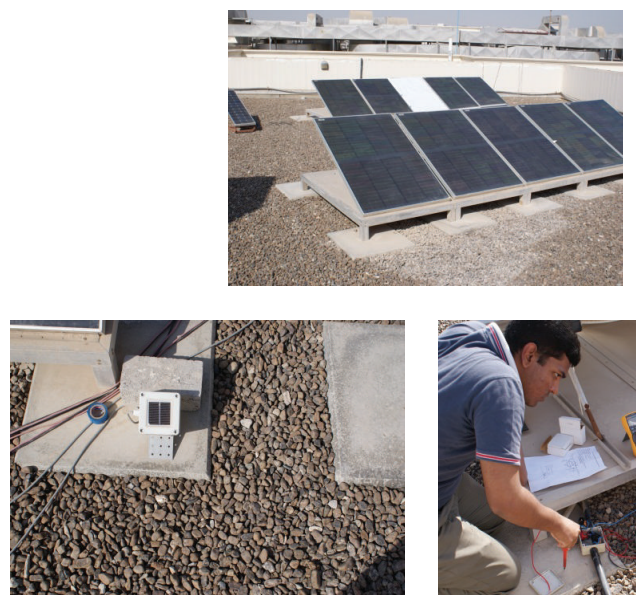

(b) PV system at the UAE Petroleum Institute

FIgURE 6: Pictures of the $I-V$ tracker and actual PV system used at the UAE Petroleum Institute.

the proposed system smoothed the $P-V$ curve shape so that it only had one peak. Therefore, the proposed system effectively minimized system losses that were a result of shading.

3.2. Experimental Analysis. The results of the simulation were validated using an existing operational PV system located at the Petroleum Institute in the United Arab Emirates (UAE). Figure 6(a) shows the $I-V$ tracker model number (PVPM 1000) used to measure the electrical characteristics of the PV system and to transfer the measured data to an Excel file. Figure 6(b) shows the actual PV system used for the experiment at UAE. The module used is a CIGS thin-film system with standard test conditions (STC) of maximum power wattage of $50 \mathrm{~W}$, maximum power voltage of $16.8 \mathrm{~V}$, and maximum power current of $3.0 \mathrm{~A}$. It has an open circuit voltage (Voc) of $25.2 \mathrm{~V}$, short circuit current (Isc) of $4.1 \mathrm{~A}$, and maximum system voltage (Vdc) of $600 \mathrm{~V}$. Measurements were taken in February during sunny days.

3.3. Error Analysis of the Experimental Results. In order to account for the device and any external factors that may impact the accuracy of the results, an experimental error analysis was performed to insure that the results are within the acceptable ranges for the purpose of this paper. The PVPM 1000C PVE $I-V$ tracker has accuracy of $1 \%$ and peak value range around $\pm 5 \%$ and all experiments that 


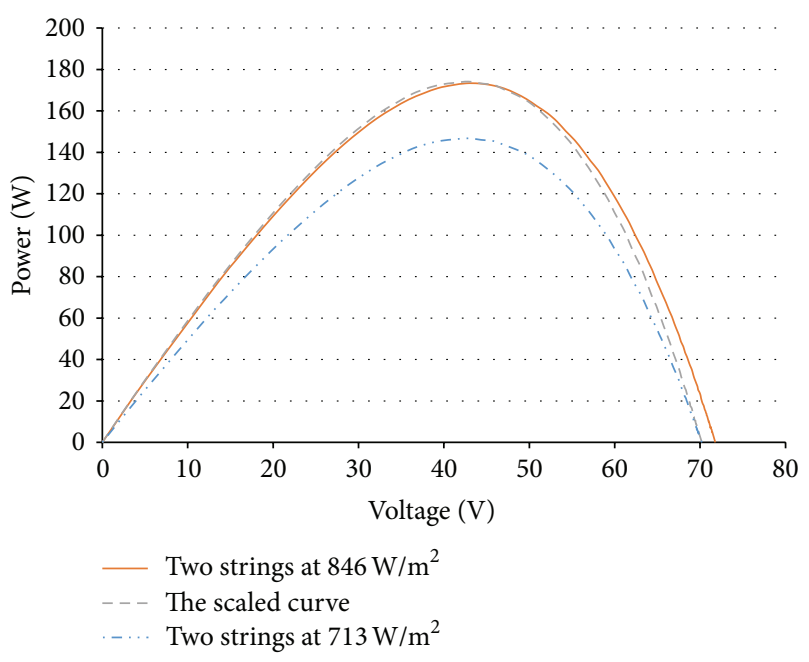

(a) The two string configuration results at different solar radiation conditions

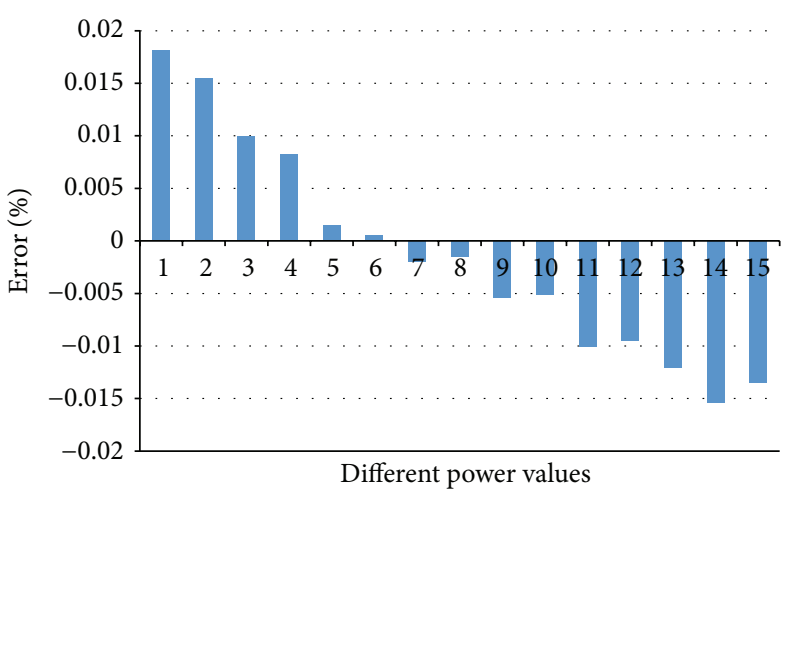

(b) PV system at the UAE Petroleum Institute

FIGURE 7: Error analysis of results.

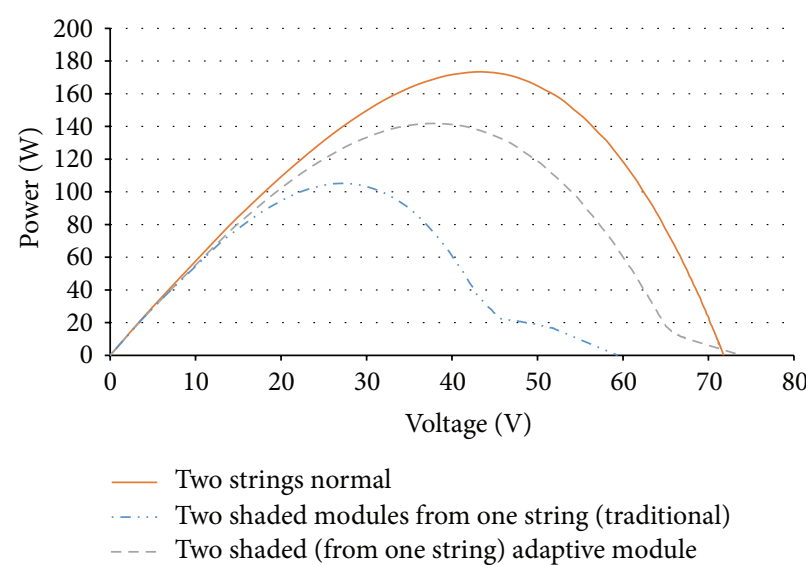

(a) Simulated results

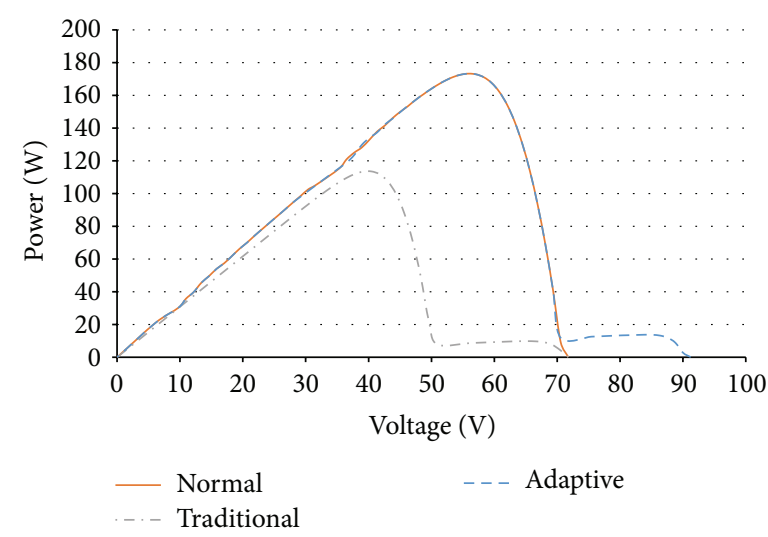

(b) Experimental results

FIGURE 8: Simulation and experimental results for traditional and proposed adaptive system with two shaded modules.

reflect comparisons in values between the traditional and the adaptive configurations were taken in clear sky conditions within period of 1 to 3 minutes that was required to switch the terminals connections to configure the adaptive verses the traditional.

It was noticed that there was a variation in the solar radiation intensity during the experiments and, in order to overcome this issue, the curves were scaled to allow a good comparison between the results of different operating conditions. Figure 7(a) shows three curves for two strings under two different solar radiation conditions. The first curve reflects the $P-V$ curve for two strings of PV modules at $846 \mathrm{~W} / \mathrm{m}^{2}$ and the other curve reflects the same experiments at $713 \mathrm{~W} / \mathrm{m}^{2}$. As can be seen, the curves peak values change because of the change in the solar radiation. The third curve in Figure 7(a) was drawn by multiplying the power values of the second curve by the factor 1.187 , which is the result of solar radiation value variation between the first and the second curves $846 / 713=1.187$. As a result, the second curve was scaled to the same solar radiation conditions and to be precise compared to the first curve. Figure 7 (b) illustrates the deviation in percentage for the peak values of the power curves that were scaled in Figure 7(a). As can be seen, the values fluctuate between the ranges of $+1.86 \%$ and $-1.53 \%$, which is an acceptable deviation.

3.4. Results and Analysis. Two shaded modules from the same string were used to compare the experimental $P-V$ curves. The normal operational conditions are illustrated by the highest peak in Figures 8(a) and 8(b). The traditional system is denoted by the multiple peak curves that have a lower peak value than the other curves, while the adaptive system is denoted by the middle curve in Figure 8(a) and overlapping curve in Figure 8(b) that are only present in 
TABLE 1: Comparison of shading losses between traditional system and the proposed system.

\begin{tabular}{lcccc}
\hline \multirow{2}{*}{ Number of shaded modules } & \multicolumn{2}{c}{ Pmax normal (no shading) } & \multicolumn{2}{c}{173.31} \\
& $\begin{array}{c}\text { Pmax [W] traditional } \\
\text { system }\end{array}$ & $\begin{array}{c}\text { Pmax [W] adaptive } \\
\text { system }\end{array}$ & $\begin{array}{c}\text { Losses in traditional } \\
\text { system }\end{array}$ & $\begin{array}{c}\text { Losses in adaptive } \\
\text { system }\end{array}$ \\
\hline One & 133.50 & 149.30 & $23 \%$ & $14 \%$ \\
Two from the same string & 88.50 & 152.16 & $49 \%$ & $12 \%$ \\
Two from different strings & 105.12 & 141.74 & $39 \%$ & $18 \%$ \\
Three from different strings & 62.31 & 143.35 & $64 \%$ & $17 \%$ \\
Four (two from each string) & 39.50 & 139.76 & $77 \%$ & $19 \%$ \\
\hline
\end{tabular}

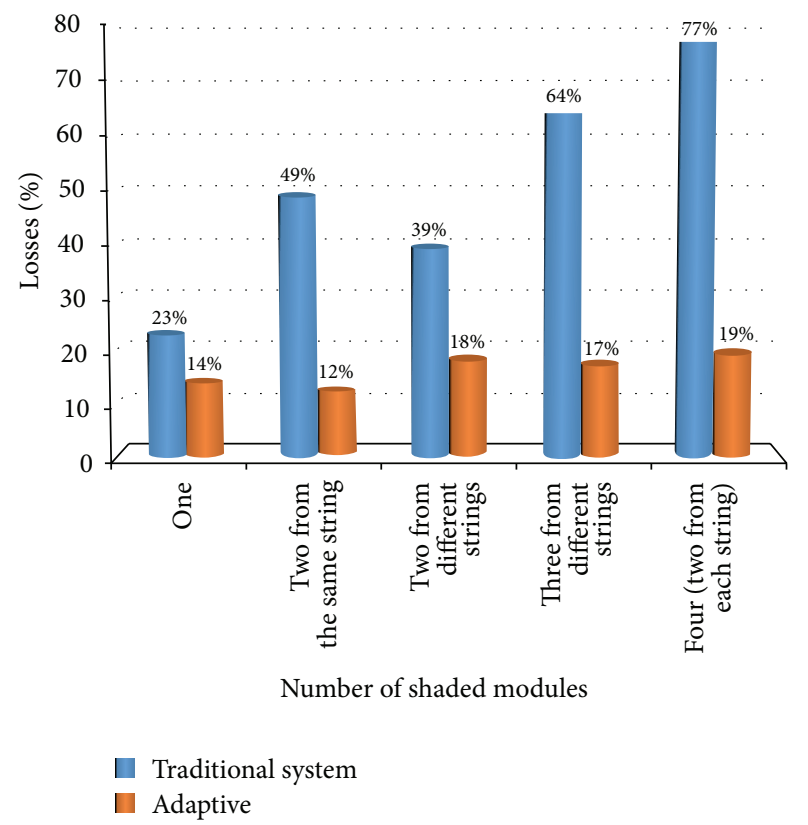

FIGURE 9: Comparison of losses between traditional and proposed adaptive system.

the simulated result. Ideally, when a module is shaded and additional modules are added to the same string, the system will return to its normal operating condition as shown in Figure $8(\mathrm{~b})$ and $P-V$ characteristics will overlap the normal condition while practical response is a little different due to the bypass diode losses and inner resistance of the shaded PV module. As can be seen, adaptive and no-shading (normal) $P-V$ curves are not identical. Figure 8(b) illustrates the difference. The most important observation is that both simulation and practical results represent one single peak in the $P-V$ curve, which is the main concern to the power conditioning units (PCUs). As discussed in the previous proposed topologies, single peak means more efficient system and fewer losses (mismatching losses).

Table 1 compares the maximum power values derived in the experimental results for each shading pattern in the traditional and proposed adaptive configurations. It also shows the losses that result from the effects of shade on each system. In the traditional system, as shown in Figure 9, the losses increase in line with an increase in the number of system modules. In the adaptive system, on the other hand, the losses decrease by an average of $16 \%$. In other words, the proposed system can minimize the mismatching losses of the solar PV array in real time by an average of $100 \%$ under simulated conditions and by $84 \%$ in practical experiments. The reduction in losses is due to the presence of additional PV modules that are able to compensate for the power and voltage drop in the shaded string. Another important observation that can be deduced from Table 1 is that energy lost as a result of use of the adaptive PV string-inverter configuration is almost constant regardless of how the shading patterns affect the system. This is a very promising result for a large PV installation.

\section{Conclusion}

This paper proposed a new method to adaptively overcome the losses in existing PV configurations due to shading and low radiation conditions. The proposed system is validated under shade conditions using a simulation and an experiment with an existing system. The results show that energy losses can be minimized and recovered. Overall, the proposed system is able to minimize the losses of the solar PV array in real time under shaded conditions by an average of $100 \%$ during simulation and by $84 \%$ in actual experimental settings. The reconfiguration allows the system to operate in its normal operating conditions especially where the invert input parameters are to be met for minimal operational conditions. The focus of this research is the development and validation of this proposed topology. Future research aspect can be focused on designing and developing the control system for this proposed topology to address timing constrains on the controller and the power electronic switches that will reconfigure the PV system and on the timing requirements along with real-time information to consider speed at which these switches operate to eliminate any discontinuity in the system to generate power and provide this power to the inverter input.

\section{Conflict of Interests}

The authors declare that there is no conflict of interests regarding the publication of this paper. They have no conflict of interests and no financial gains in mentioning where the work took place or the affiliation of the authors. 


\section{Acknowledgments}

This work was supported in part by the Environmental Protection Agency (EPA), Grant no. CR-83419301-1. They would like to also thank the Petroleum Institute, United Arab Emirates (UAE), for their support in the experimental phase of this project.

\section{References}

[1] IEA, International Energy Agency International Energy Outlook 2014, 2014, http://www.iea.org/Textbase/npsum/WEO2014SUM .pdf.

[2] International Energy Agency, Technology Roadmap Solar Photovoltaic Energy, IEA, 2014, http://www.iea.org/publications/freepublications/publication/technology-roadmap-solar-photovoltaic-energy-2014-edition.html.

[3] A. F. Abdul Kadir, T. Khatib, and W. Elmenreich, "Integrating photovoltaic systems in power system: power quality impacts and optimal planning challenges," International Journal of Photoenergy, vol. 2014, Article ID 321826, 7 pages, 2014.

[4] Y. Huang, C. Chan, S. Kuan, S. Wang, and S. Lee, "Analysis and monitoring results of a building integrated photovoltaic façade using PV ceramic tiles in Taiwan," International Journal of Photoenergy, vol. 2014, Article ID 615860, 12 pages, 2014.

[5] Y.-L. Chen, C.-W. Yu, Z.-J. Chien, C.-H. Liu, and H.-H. Chiang, "On-road driver monitoring system based on a solarpowered in-vehicle embedded platform," International Journal of Photoenergy, vol. 2014, Article ID 309578, 12 pages, 2014.

[6] M. C. Brito, N. Gomes, T. Santos, and J. A. Tenedório, "Photovoltaic potential in a Lisbon suburb using LiDAR data," Solar Energy, vol. 86, no. 1, pp. 283-288, 2012.

[7] US Energy Information Administration, Annual Energy Outlook 2014, US Energy Information Administration, 2014, http://www.eia.gov/forecasts/aeo/pdf/0383.

[8] K. W. R. Chew and L. Siek, "Single inductor quad-input-dualoutput buck converter for photovoltaic systems," in Proceedings of the 36th Annual Conference of the IEEE Industrial Electronics Society (IECON '10), pp. 704-709, Glendale, Ariz, USA, November 2010.

[9] D. Nguyen and B. Lehman, "An adaptive solar photovoltaic array using model-based reconfiguration algorithm," IEEE Transactions on Industrial Electronics, vol. 55, no. 7, pp. 26442654, 2008.

[10] C. Chang, "Solar cell array having lattice or matrix structure and method of arranging solar cells and panels," US Patent 6635 817, October 2003.

[11] R. A. Sherif and K. S. Boutros, "Solar module array with reconfigurable tile," US Patent 6350944, 2002.

[12] G. Velasco-Quesada, F. Guinjoan-Gispert, R. Piqué-López, M. Román-Lumbreras, and A. Conesa-Roca, "Electrical PV array reconfiguration strategy for energy extraction improvement in grid-connected PV systems," IEEE Transactions on Industrial Electronics, vol. 56, no. 11, pp. 4319-4331, 2009.

[13] Y. Auttawaitkul, B. Pungsiri, K. Chammongthai, and M. Okuda, "A method of appropriate electrical array reconfiguration management for photovoltaic powered car," in Proceedings of the IEEE Asia-Pacific Conference on Circuits and Systems (APCCAS '98), pp. 201-204, IEEE, Chiang Mai, Thailand, November 1998.

[14] Z. M. Salameh and C. Liang, "Optimum switching point for array reconfiguration controllers," in Proceedings of the IEEE 21st Photovoltaic Specialists Conference (PVSEC '90), vol. 2, pp. 971-976, Kissimmee, Fla, USA, May 1990.

[15] Y. Wang, X. Lin, Y. Kim, N. Chang, and M. Pedram, "Architecture and control algorithms for combating partial shading in photovoltaic systems," IEEE Transactions on Computer-Aided Design of Integrated Circuits and Systems, vol. 33, no. 6, pp. 917930, 2014.

[16] J. Storey, P. R. Wilson, and D. Bagnall, "The optimized-string dynamic photovoltaic array," IEEE Transactions on Power Electronics, vol. 29, no. 4, pp. 1768-1776, 2014.

[17] M. Alahmad, M. A. Chaaban, S. K. Lau, J. Shi, and J. Neal, "An adaptive utility interactive photovoltaic system based on a flexible switch matrix to optimize performance in real-time," Solar Energy, vol. 86, no. 3, pp. 951-963, 2012.

[18] M. A. Alahmad and H. L. Hess, "Evaluation and analysis of a new solid-state rechargeable microscale lithium battery," IEEE Transactions on Industrial Electronics, vol. 55, no. 9, pp. 33913401, 2008

[19] M. Alahmad and H. Hess, "Microwave SOI based design of a power management system for JPL's rechargeable micro-scale batteries," IET Circuits, Devices \& Systems, vol. 4, no. 3, pp. 261$268,2010$.

[20] H.-F. Tsai and H.-L. Tsai, "Implementation and verification of integrated thermal and electrical models for commercial PV modules," Solar Energy, vol. 86, no. 1, pp. 654-665, 2012.

[21] S. Rajesh, Hybrid power system modeling-simulation and energy management unit development [A Dissertation in Candidacy for the Degree of Doctor in Engineering], 2008.

[22] E. F. M. Kheswa and I. E. Davidson, "Model of a photovoltaic fuel-cell generator," in Proceedings of the 7th AFRICON Conference in Africa: Technology Innovation, pp. 735-739, IEEE, September 2004.

[23] H. Patel and V. Agarwal, "MATLAB-based modeling to study the effects of partial shading on PV array characteristics," IEEE Transactions on Energy Conversion, vol. 23, no. 1, pp. 302-310, 2008. 

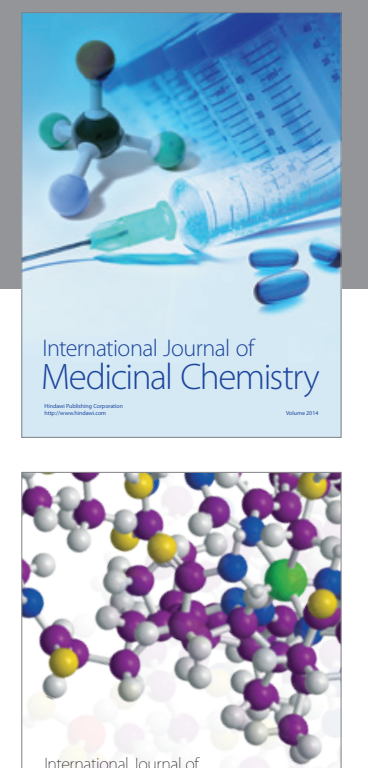

\section{Carbohydrate} Chemistry

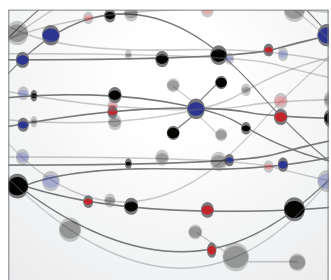

The Scientific World Journal
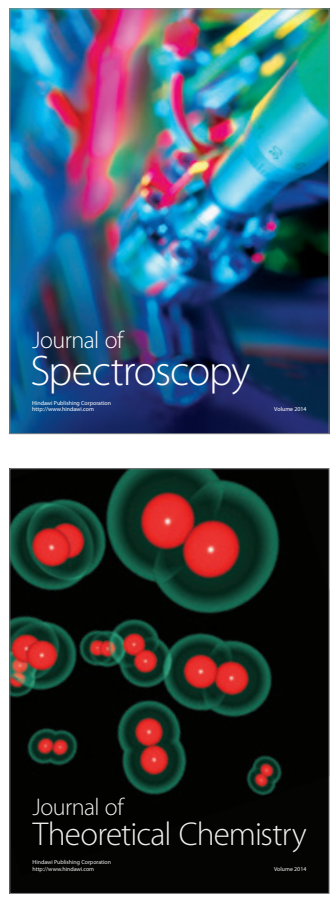
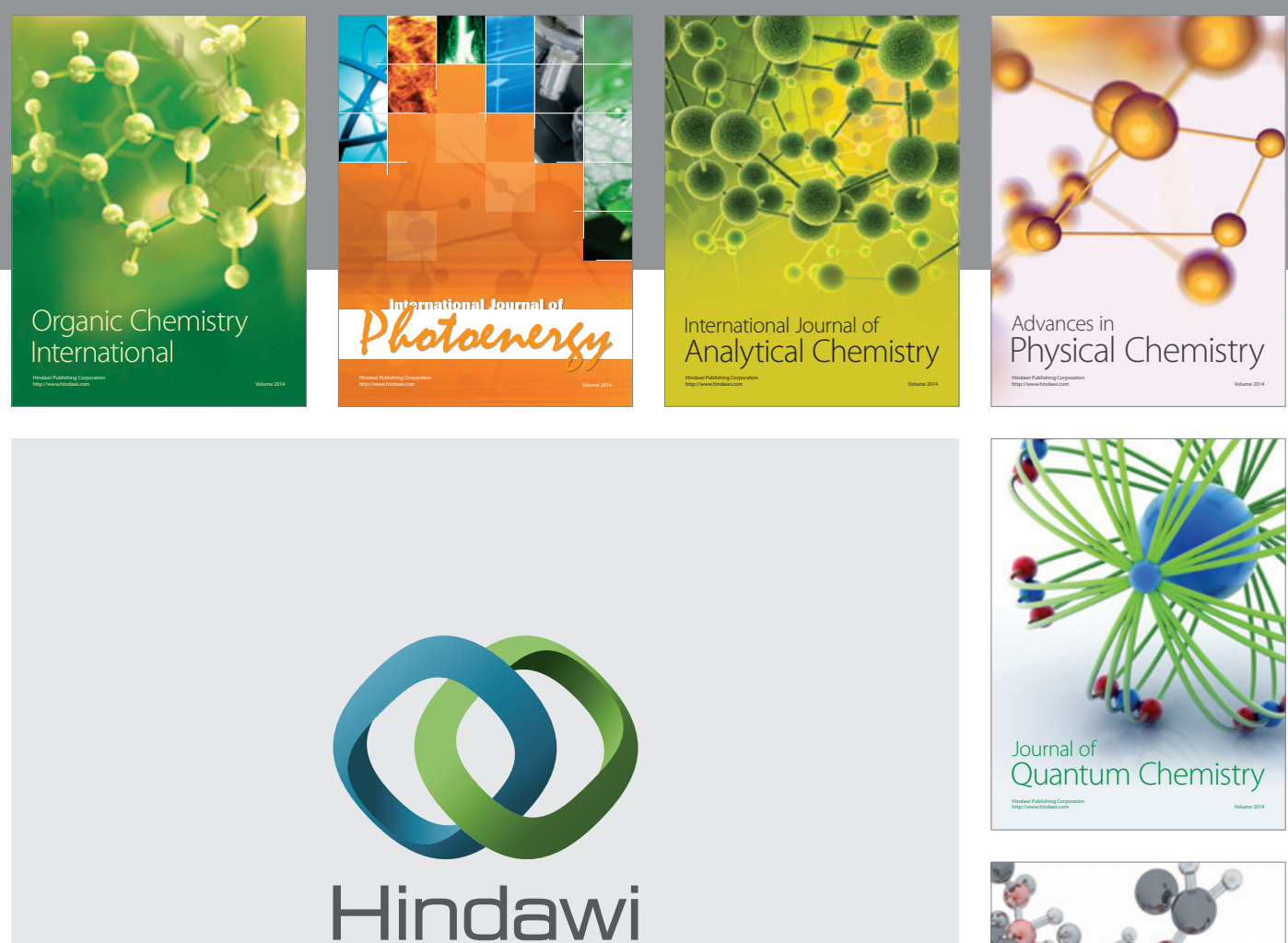

Submit your manuscripts at

http://www.hindawi.com

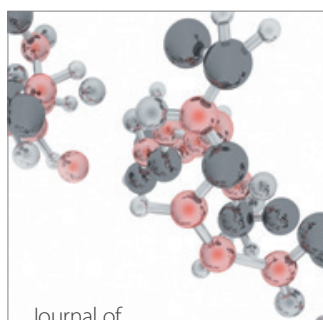

Analytical Methods

in Chemistry

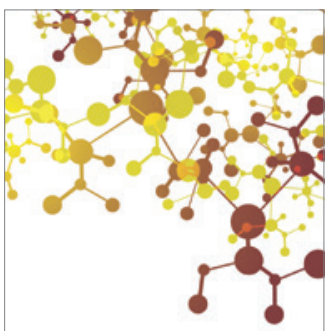

Journal of

Applied Chemistry

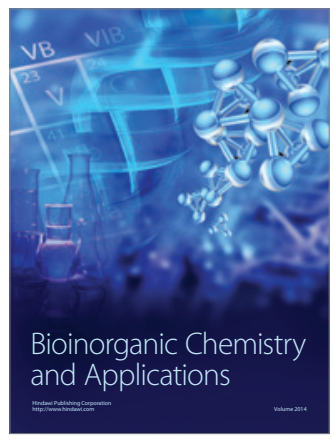

Inorganic Chemistry
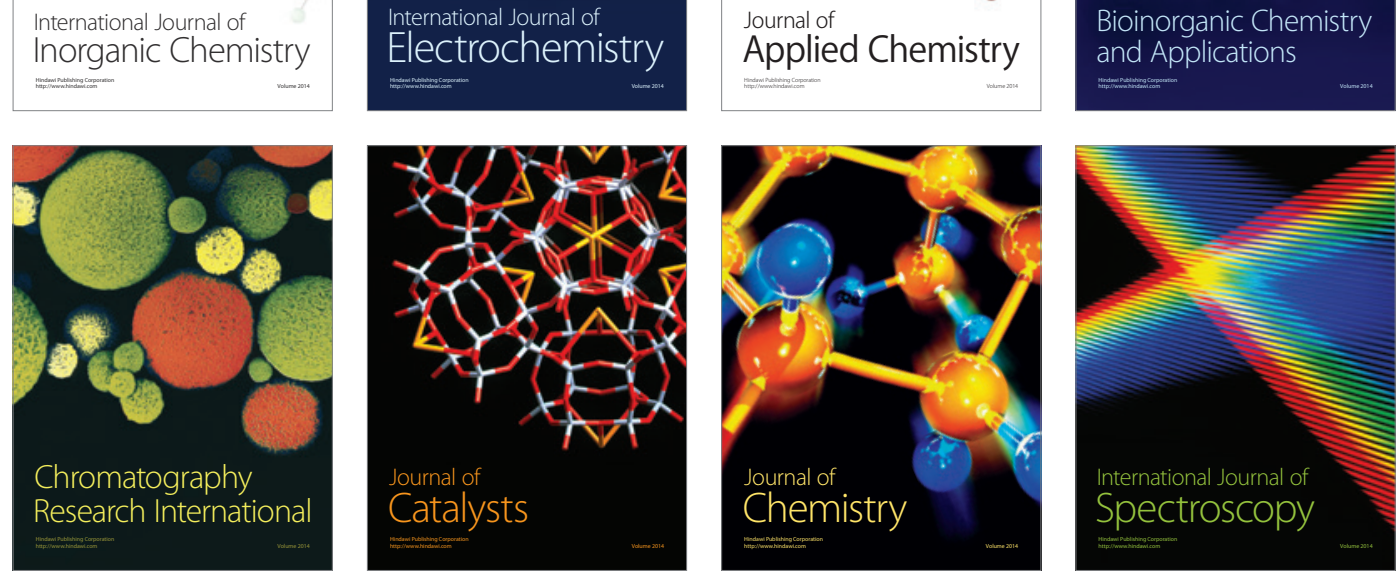